\title{
Regulating an Experience Good Produced in the Formal Sector of a Developing Country when Consumers Cannot Identify Producers
}

\author{
Timothy McQuade, Stephen Salant, and Jason Winfree*
}

\begin{abstract}
In developing countries, consumers can buy many goods either in formal markets or in informal markets and decide where to purchase based on the product's price and anticipated quality. This pape assumes consumers cannot assess quality prior to purchase and cannot, at reasonable cost, identify who produced the good they are considering. Many products (meats, fruits, vegetables, fish, grains) sold both in formal groceries and, less formally, on the street fit this description. This paper also assumes that producers can adjust quality at a cost and only firms in the formal sector are subject to government regulation. In the long run, producers migrate to the sector that is more profitable. Using this model, we demonstrate how regulations in the formal sector can lead to a quality gap between formal and informal sector goods. Moreover, the paper investigates how changes in regulation affect quality, price, aggregate production, and the number of firms in each sector.
\end{abstract}

\section{Introduction}

In developing countries, informal markets co-exist alongside formal markets. Contrary to the conventional view that the informal sector produces intermediate goods for the formal sector, in many cases, the same kinds of goods and services are provided by both sectors and are in fact manufactured by similar processes. Empirical studies (e.g. Myint, 1985; Livingstone, 1991) have documented a "quality gap" between the outputs of the two sectors. Goods produced in the formal sector are, on average, of higher quality and more expensive than those produced in the informal sector.

Banerji and Jain (2007) have recently provided one possible explanation for this "quality dualism." In their model, the formal sector is characterized by higher wages and lower rentals and firms decide which sector to be in. Given this exogenous difference in factor prices and the assumption that higher quality goods are more capitalintensive, the formal sector firms can make high quality products more cheaply and the informal sector firms can make low quality products more cheaply. Since consumers differ in how much they are willing to pay for better quality, both sectors have a demand for their products.

However, Banerji and Jain cannot explain much of the quality dualism in developing countries since their explanation requires that consumers ascertain quality prior to

\footnotetext{
* Winfree (corresponding author): Program in Sport Management, University of Michigan, Observatory Lodge, 1402 Washington Heights, Ann Arbor, Michigan 48109, USA. Tel: +1-734-647-5424; Fax: +734-6472808; E-mail:jwinfree@umich.edu. McQuade: Department of Economics, Harvard University, 1805 Cambridge Street, Cambridge, MA 02138, USA. E-mail: tmcquade@fas.harvard.edu. Salant, Department of Economics, University of Michigan, 254 Lorch Hall, 611 Tappan Street, Ann Arbor, MI 48109-1220, USA. E-mail: ssalant@umich.ed. We would like to thank Jim Adams, Axel Anderson, Heski Bar-Isaac, Tilman Börgers, Will Fogel, Wenting Hu, Ravi Kanbur, Greg Lewis, Tom Lyon, Shaun MacRae, Jill McCluskey, Marc Melitz, Edward Okeke, Ariel Pakes, Nicola Persico, Megan Sheahan, and two anonymous referees for helpful comments and insights.
} 
purchase. In this paper, we explain how a quality gap can arise when their assumption fails to hold. The quality of some goods can be determined by a simple inspection prior to purchase, but in many other cases, the quality of a good can be determined only after consuming it. Such "experience goods" can be classified into two categories: in the first, a consumer can costlessly identify the producer of the good; in the second, the consumer cannot at reasonable cost identify its producer. ${ }^{1}$ It is the latter which we consider in this paper.

Even in developed countries, this second class of consumer goods is not uncommon. When we buy a Washington apple, we do not know how it will taste and we cannot ascertain what orchard produced it. Moreover, globalization has raised the frequency with which consumers in developed countries encounter such products (McQuade et al., 2012), but the inability to trace an experience good to its producer is even more common in developing countries regardless of whether the good is sold in the formal or informal market.

Consider some examples. Fruits, vegetables, meats, fish, grains, coffee beans, videos, and other goods are sold both in formal stores and on the street in the informal market. The quality (both the taste and the health consequences) of consuming these goods is uncertain prior to purchase; often the purchase must be made without knowing who grew or manufactured the product. Cooking oil in India is sold both in groceries and on the street. In either case, a consumer does not know whether it has been adulterated, nor is the source of the oil easy to determine. The same is true of maize in Kenya. A consumer can buy it in a grocery or on the street, but in either case, there is uncertainty about whether it has been stored improperly and become contaminated with aflatoxin, a fungus that cannot be detected by casual visual inspection. Panela, a sugar produced in massive quantities in Colombia and elsewhere in Latin America, is another example of a good sold in both formal and informal markets. In each case, the quality is impossible to ascertain prior to purchase, and any of a large set of households or firms might have produced it.

When the consumer cannot identify the producer of an experience good prior to purchase, he must base his expectation of the product's quality on something else. We assume here that he can identify the sector which produced the good. Knowing the quantity of goods of each quality produced by that sector, he anticipates that the quality of the good he is considering equals the quantity-weighted average quality of goods from that sector.

This informational environment puts producers of such goods in a difficult position. They know the quality of the goods they produce, but they realize that there is no way for a potential buyer to distinguish the quality of their product from the quality of the other products lumped together in the consumer's mind. They recognize, therefore, that they share a "collective reputation." Not surprisingly, a producer does not have as much incentive to make a product of high quality as he would if consumers distinguished his products from those of his competitors. ${ }^{2}$

The literature on "collective reputation" investigates what happens in such situations. All firms sell the experience good at a common price and share a common reputation for quality. The first paper in this literature was Winfree and McCluskey (2005). ${ }^{3}$ In their model, output is exogenous, entry is prohibited, and every firm is constrained to offer a single quality rather than a product line. Most recently, McQuade et al. (2012) relax the assumption of fixed output and prove that no firm would choose to produce more than one quality if the constraint in the literature is relaxed.

In this paper, we consider $n$ producers of a single experience good. While in the short run firms are exogenously assigned to the formal or the informal sector, in the 
long run firms are free to costlessly move between the two. Producers operating in the formal sector always sell the good to consumers through perfectly competitive outlets in the formal market, while producers in the informal sector sell the good through outlets in the informal market. Consumers may patronize either market (or neither market).

One issue which we have heretofore neglected is what we mean by "formal" and "informal." Since these terms have not always been used consistently in the literature, it is important to be precise. Some analysts distinguish the two sectors by endogenous market variables, as in Banerji and Jain (2007). Just why the sectors display this difference in factor prices is outside their formal model, but they attribute it to government regulation. Other analysts center the distinction between the two sectors on regulation. ${ }^{4}$ Mazumdar (1983) defines formal labor markets as markets that have labor laws or unions. Marjit et al. (2007) assume that informal markets imply illegal production. In Rauch (1991) minimum wage regulations are imposed only on firms of above a certain size.

In our paper, producers that submit to government regulation are said to be in the formal sector while firms that fly under the regulatory radar are said to be in the informal sector. If the government removed every regulation from formal sector producers, then, in the long run as firms re-allocate themselves, the sectors would be of equal size and every firm would produce goods of the same quality regardless of the sector it was in, and these goods would sell for the same price (our Theorem 1). This is consistent with the observation of Castells and Portes (1989, p. 13) that "with no regulation of any kind, the distinction between formal and informal would lose meaning." 5

Introducing a regulatory structure creates a meaningful distinction between the formal and informal sector and can endogenously lead to a quality gap in the output of the two sectors. One simple policy instrument which generates quality dualism and which has received considerable attention in the development literature is taxation. ${ }^{6}$ In our model, as taxes are levied on formal sector producers, the long run equilibrium is characterized by an informal sector which is larger than the formal sector and produces lower quality, lower priced goods. This is because the introduction of taxes leads firms to migrate from the formal sector to the informal sector in order to escape the tax burden. This leads to an expansion of the informal sector and a contraction of the formal sector, thereby exacerbating the collective reputation problem in the informal sector, while ameliorating it in the formal sector. As a result, quality decreases in the informal sector and increases in the formal sector. Since consumers can patronize either market and require lower prices for goods expected to be of lower quality, informal market goods must sell for less than formal market goods.

Note that regulation of the formal sector will affect firm behavior in the informal sector. The economics literature on the formal and informal sectors has long recognized that regulating the formal sector will have such spillover effects. Most recently, for example, Marjit and Kar (2011) consider a Hecksher-Ohlin-Samuelson (HOS) model with each good produced in both the formal and informal sectors. Each good is of known and invariant quality. Marjit and Kar show that a decline in tariff rate should increase the informal wage in a developing economy.

Not all government regulation would lead firms in the formal sector to produce higher quality goods. For example, a subsidy per unit produced in the formal sector would lead to a long-run equilibrium with a larger formal sector and with the informal sector producing the higher quality goods. A binding minimum quality standard imposed exclusively on firms in the formal sector eliminates the collective reputation of firms in that sector and will attract firms from the informal sector. In the long run 
equilibrium all firms, including those outside the ambit of regulation (i.e. firms in the informal sector), produce at the quality level specified by the standard. Hence, the government could use regulation to eliminate the quality gap and to achieve socially optimal quality provision in each sector.

In the next section, we introduce our model. In section 3 we discuss the effects of regulation on the two sectors in the short and long run. Section 4 concludes.

\section{Short and Long-run Equilibrium in the Absence of Regulation}

We consider a country in which a single experience good is produced in both a formal $(F)$ and an informal $(I)$ sector. The formal sector is visible to the government and is subject to regulation. Conversely, the informal sector consists of producers that operate beyond government scrutiny and are therefore not subject to regulation. We suppose that there are $n$ producers of the final good, which operate in at most one sector. For simplicity, we do not require that $n$ be an integer. In the short run, producers are assigned exogenously to sectors; in the long run, the producers migrate to the sector which is more profitable. ${ }^{7}$ Each producer, denoted by $i$, in sector $j$ for $j \in\{F, I\}$ sets quality $k_{i j} \in[0, \infty)$ and quantity $q_{i j} \in[0, \infty)$ simultaneously to maximize profits given the conjectured behavior of the other firms and the anticipated decision rules of the consumers.

A consumer gets net utility $u$ from purchasing one unit of quality $k$ at price $p$ : $u=\theta k-p$. Each consumer has an outside option $\bar{u}$ and buys the experience good if and only if it provides higher net utility than his outside option. We assume that consumers have the same $\theta$ but different outside options. ${ }^{8}$

Consumers purchase the experience good from perfectly competitive sellers operating in either the formal market or informal market. We assume that sellers in the formal market obtain the good only from producers in the formal sector, while sellers in the informal market obtain it only from producers in the informal sector. Consumers form independent views about the quality of the goods being sold in the formal and informal markets but cannot trace a good to a particular producer. Instead, consumers only know the distribution of quality among producers in each sector. Since consumers are assumed to be risk neutral, it therefore follows that the expected utility of purchasing the experience good in either the formal or informal market at price $p$ is given by $u=\theta R^{j}-p$, where:

$$
R^{j}=\sum_{i=1}^{n_{j}} \frac{q_{i j}}{Q^{j}} k_{i j} .
$$

Here $n_{j}$ is the number of producers in sector $j$ and $Q^{j}$ is the total quantity of the good produced by sector $j$. In other words, every producer in a particular sector shares the same collective reputation for quality equal to the quantity-weighted average of qualities in that sector. Because consumers cannot trace an individual good to its producer, there is a single price $P^{F}$ in the formal market and a single price $P^{I}$ in the informal market.

Consumers observe the average qualities and prices of goods sold in the formal and informal markets, respectively. Shoppers compare $\theta R^{F}-P^{F}, \theta R^{I}-P^{I}$, and $\bar{u}$, and patronize the source providing the highest net expected utility. In the event of ties, consumers may patronize multiple sources. In equilibrium, prices adjust so that consumers are indifferent between purchasing the experience good on either the formal market or informal market but may strictly prefer both to their outside options. Prices 
depend on the aggregate supply of the experience good produced in the two sectors. Suppose that, for the given distribution of outside options, a utility of $G$ must be offered to attract $Q$ customers to the experience good. We assume that $G(Q)$ is a strictly increasing, strictly convex, and twice differentiable function and that $G(0)=0$. $G(Q)$ reflects the distribution of the reservation utilities of the heterogeneous consumers. ${ }^{9}$ In equilibrium, everyone purchasing the experience good on either the formal or informal market receives the same net expected utility $G(Q)$. Some patrons (the inframarginal buyers) strictly prefer the experience good to their outside option; other patrons (the marginal buyers) are indifferent between the experience good and the outside option, both of which yield net utility $G(Q)$.

More formally, let the inverse demand of sector $j(j=F, I)$ be given by:

$$
P^{j}\left(Q, R^{j}\right)= \begin{cases}\theta R^{j}-G(Q) ; & \text { if } Q<G^{-1}\left(\theta R^{j}\right) \\ 0 ; & \text { if } Q \geq G^{-1}\left(\theta R^{j}\right) .\end{cases}
$$

The inverse demand curves for the goods produced in each sector is strictly increasing in that sector's reputed quality, strictly decreasing and strictly concave in the total output of the two sectors, and additively separable in the two variables over the set $\left\{\left(Q, R_{j}\right) \mid Q<G^{-1}\left(\theta R^{j}\right)\right\}$.

Suppose ex-ante there are $n_{F}$ producers registered in the formal sector and $n_{I}$ producers operating in the informal sector. Also, for the moment consider the benchmark with no regulations. Consider the game where each producer $i\left(i=1, \ldots, n_{j}\right)$ in sector $j$ $(j=F, I)$ simultaneously chooses its output and quality to maximize the following payoff function:

$$
q_{i j}\left[P\left(q_{i j}+Q_{-i j}, R^{j}\right)-c\left(k_{i j}\right)\right]
$$

where $c\left(k_{i j}\right)$ is the strictly increasing, convex per unit cost if output is of quality $k_{i j}>0$; in addition, $c(0)=c^{\prime}(0)=0$.

When the other firms in sector $j$ are producing $\left(Q_{-i j}>0\right)$, then the reputed quality of sector $j$ is well defined whether or not firm $i$ is producing. Hence, equation (3) is well defined. When no firm in sector $j$ is producing, however, the reputed quality of that sector is ambiguous, and we define the profit of firm $i$, given in equation (3), as zero. This assignment never conflicts with (3), as that equation, evaluated at $q_{i j}=0$, gives the same result when $Q_{-i j}>0$ and is undefined when $Q_{-i j}=0$.

Because firm $i$ maximizes profits, its decisions must satisfy the following pair of complementary slackness (denoted c.s.) conditions for $Q_{-i j}>0$ :

$$
\begin{aligned}
& q_{i j} \geq 0, \quad \theta R^{j}-G(Q)-c\left(k_{i j}\right)-q_{i j} G^{\prime}(Q)+q_{i j} \theta \frac{\partial R^{j}}{\partial q_{i j}} \leq 0, \quad \text { c.s. } \\
& k_{i j} \geq 0, \quad q_{i j}\left[\theta \frac{\partial R^{j}}{\partial k_{i j}}-c^{\prime}\left(k_{i j}\right)\right] \leq 0, \quad \text { c.s. }
\end{aligned}
$$

where, from (1), $\frac{\partial R^{j}}{\partial k_{i j}}=q_{i j} / Q^{j}$ and $\frac{\partial R^{j}}{\partial q_{i j}}=\left(k_{i j}-R^{j}\right) / Q^{j}$. In the appendix, we show that there exist no Nash equilibria of the game where firms within a sector use differing strategies. We also establish that conditions (4) and (5), which must hold at any Nash equilibrium, have only one solution where firms within a sector follow symmetric strategies and receive a strictly positive price. This unique solution constitutes a Nash 
equilibrium whenever all firms are active and none can make a nonlocal, profitable deviation. ${ }^{10}$ In the Nash equilibrium, every firm in a sector $j$ sells the same unique, strictly positive amount $\left(q_{i j}=q_{j}>0\right.$, for all $\left.i\right)$ at the same unique, strictly positive quality $\left(k_{i j}=k_{j}>0\right.$, for all $\left.i\right)$. It follows that $\frac{d R^{j}}{d k_{i j}}=\frac{1}{n_{j}}$ and $\frac{d R^{j}}{d q_{i j}}=0$.

We can rewrite the first-order conditions (4) and (5) as follows:

$$
\theta R^{j}-G(Q)-c\left(k_{j}\right)-q_{j} G^{\prime}(Q)=0
$$

and

$$
\theta \frac{1}{n_{j}}-c^{\prime}\left(k_{j}\right)=0 \quad \text { for } \quad j=F, I
$$

Equation (6) is a familiar Cournot first-order condition. It indicates that the firm should increase production until its per-unit profit from expanding output by another unit $\left(\theta R^{j}-G(Q)-c\left(k_{j}\right)\right)$ just equals the losses $\left(q_{j} G^{\prime}(Q)\right)$ this expansion would impose because of the induced price reduction on the other units the firm was selling. Equation (7) indicates that each producer in a given sector raises the quality of its output until the marginal cost of further expansion $\left(c^{\prime}\left(k_{j}\right)\right)$ equals the marginal benefit of that expansion $\left(\frac{\theta}{n_{j}}\right)$. Note that a producer incurring the additional cost of increasing quality captures only $1 / n_{j}$ th of the benefit since the firm produces only $1 / n_{j}$ of sector j's output.

We assume that in the short run, the number of producers in each sector is set at its exogenously specified level. However, we suppose that in the long run it is costless for a producer to move between the formal and informal sectors. This leads to the following result:

THEOREM 1. The laissez-faire benchmark: in the short run, the output from the sector with the larger number of producers will be of lower quality and will sell for a lower price; firms operating in this sector will produce less output and make smaller profits. In the long run, the number of producers operating in each sector will equalize and all firms will produce the same volume of output; quality, price and profits will equalize among producers in the two sectors.

Proof. Equation (7) implies that the sector with the larger number of firms will offer lower-quality experience goods. Because prices adjust so that consumers are indifferent about the source of the good, output in the sector with the larger number of producers must sell at a lower price. This in turn ensures that every firm operating in the larger sector has lower profit and output, as the following argument shows. In the equilibrium, any firm offering quality $k$ earns profit per unit of $\theta k-G(Q)-c(k)$. As this function is strictly concave in quality and peaks at $k^{*}$, the implicit solution to $\theta=c^{\prime}(k)^{*}$, equation (7) implies that in equilibrium, every firm will choose a quality $k_{j}<k^{*}$. Therefore, the profit per unit at each firm in a group rises if the common quality of every firm in that group increases. It follows that firms in the larger sector will have lower profit per unit than firms in the smaller sector, but equation (6) implies that any firm with a lower profit per unit produces less output and hence earns lower total profit. ${ }^{11}$ In the limiting case where each sector has the same number of 
firms, quality, price, output, and profit are the same at every firm regardless of its sector.

In long-run equilibrium, because switching between sectors is costless, producers will reallocate themselves until the profits earned in the formal market are equal to the profits earned in the informal sector. Moreover, producers in each sector are free to adjust their output until the per-unit profit of expanding output equals the losses that would be imposed on the inframarginal units sold by a firm. Consequently, profits at a firm in sector $j$ will equal $q_{j}^{2} G^{\prime}(Q)$ for $j=F, I$. It follows that in the long-run equilibrium, output will equalize among firms in the two sectors, and so will profit per unit. This implies that quality must be equalized across sectors and so number of firms must be equalized across sectors.

\section{Consequences of Two Policies}

Suppose that the formal and informal sectors are in long-run equilibrium so that the number of firms operating in each sector is equal, and profits, output, and qualities equalize across sectors. Assume the government enacts a regulation binding only on firms in the formal sector. We will first consider the impact of a constant tax per-unit $(\tau)$ on firms operating in the formal sector. We have the following result:

THEOREM 2. If an equal number of firms are initially located in each sector, then in the short run, the imposition of a per-unit tax $(\tau>0)$ on the formal sector will leave quality unchanged in both sectors and will decrease aggregate output. Output, profit per firm, and profit per unit will decrease in the formal sector and increase in the informal sector.

In the long run, producers will migrate from the formal to the informal sector, and those remaining in the formal sector will offer higher qualities and higher prices than firms in the informal sector. Output per firm expands in the formal sector and contracts in the informal sector. Profits equalize across sectors.

Proof. When the regulations are imposed, each sector has an equal number of producers. Given the imposition of the tax, we can write the first-order conditions of the firms in the formal sector as:

$$
\begin{aligned}
& \theta R^{F}-G(Q)-\left(c\left(k_{F}\right)+\tau\right)-q_{F} G^{\prime}(Q)=0, \\
& \theta \frac{1}{n_{F}}-c^{\prime}\left(k_{F}\right)=0 .
\end{aligned}
$$

The first-order conditions of firms in the informal sector are unchanged. From this, one can immediately see that in the short run, the imposition of the tax has no impact on the quality choices of the firms. We can show that:

$$
\begin{aligned}
& \frac{d q_{F}}{d \tau}=\frac{-\left(G^{\prime}(Q)+q_{F} G^{\prime \prime}(Q)\right) \frac{d Q}{d \tau}-1}{G^{\prime}(Q)}<0, \\
& \frac{d q_{I}}{d \tau}=\frac{-\left(G^{\prime}(Q)+q_{I} G^{\prime \prime}(Q)\right) \frac{d Q}{d \tau}}{G^{\prime}(Q)}>0 .
\end{aligned}
$$


Using the fact that $\frac{d Q}{d \tau}=n_{F} \frac{d q_{F}}{d \tau}+n_{I} \frac{d q_{I}}{d \tau}$, we get that:

$$
\frac{d Q}{d \tau}=\frac{-n_{F}}{\left(1+n_{F}+n_{I}\right) G^{\prime}(Q)+\left(n_{F} q_{F}+n_{I} q_{I}\right) G^{\prime \prime}(Q)}<0 .
$$

As (12) indicates, the tax must decrease aggregate production; every term in the denominator of (12) is strictly positive. Given this induced aggregate contraction, the tax must cause every firm in the informal sector to expand (as (11) indicates). As for firms in the formal sector, the tax must cause them to contract as (10) reflects (otherwise every firm would expand, contradicting the result established above that aggregate production contracts). Because both factors in the last term of equation (8) decrease, after-tax profit per unit in the formal market decreases as well. Thus, profits in the formal sector decrease. Profits must increase in the informal sector. This follows because the tax raises output per firm in the informal sector andbecause consumer utility decreases-must result in a higher price and profit per unit.

In the long run, producers operating in the formal sector will move to the informal sector to take escape the tax. In other words, $n_{F}$ will decrease and $n_{I}$ will increase. From the first-order conditions, it is easy to see that the reputed quality will increase in the formal market and will decrease in the informal market. In particular, we have

$$
\frac{d k_{F}}{d n_{I}}=\frac{c^{\prime}\left(k_{F}\right)}{n_{F} c^{\prime \prime}\left(k_{F}\right)}>0, \quad \frac{d k_{I}}{d n_{I}}=\frac{-c^{\prime}\left(k_{I}\right)}{n_{I} c^{\prime \prime}\left(k_{I}\right)}<0 .
$$

We can also calculate that

$$
\begin{aligned}
& \frac{d q_{F}}{d n_{I}}=\frac{\left(\theta-c^{\prime}\left(k_{F}\right)\right) \frac{d k_{F}}{d n_{I}}-\left(G^{\prime}(Q)+q_{F} G^{\prime \prime}(Q)\right) \frac{d Q}{d n_{I}}}{G^{\prime}(Q)}, \\
& \frac{d q_{I}}{d n_{I}}=\frac{\left(\theta-c^{\prime}\left(k_{I}\right)\right) \frac{d k_{I}}{d n_{I}}-\left(G^{\prime}(Q)+q_{I} G^{\prime \prime}(Q)\right) \frac{d Q}{d n_{I}}}{G^{\prime}(Q)} .
\end{aligned}
$$

Aggregate output may either expand or contract in response to the reallocation of firms across the two sectors. However, in both cases, output per firm expands in the formal sector and contracts in the informal sector. ${ }^{12}$ Firms will continue to move from the informal sector to the formal sector until profits are equalized. In long-run equilibrium, the formal sector will be smaller and will offer higher quality goods at higher price relative to the informal sector.

This result illustrates the surprising effects of the ability of firms to move in and out of the formal and informal sectors. Due to the additive separability of the inverse demand function, a tax affects only the quantity decisions of producers in the formal sector but the changes in volume do not induce any changes in the quality of the goods produced. In the short run, the tax also has no affect on quality in the informal sector since the number of firms in that sector does not change. However, the tax does 
still affect the profits of producers operating in the formal sector, which in the long run incentivizes firms operating in the formal sector to move to the informal sector. This has the effect of raising the reputed quality in the formal market and lowering the reputed quality in the informal market. ${ }^{13}$

We now analyze the case where the government decides to regulate the quality of the product in the formal market in the form of a minimum quality standard. ${ }^{14} \mathrm{We}$ assume that the standard $(\bar{k})$ is binding on firms in the formal sector but is not set higher than the firm would choose if it were the only domestic producer, and hence its products could be readily identified by consumers.

That is, we assume $\bar{k} \leq k^{*}$, where $k^{*}$ solves $\theta=c^{\prime}\left(k^{*}\right)$. Note that $k^{*}$ is also the optimal quality chosen by a social planner to maximize welfare. We establish the following:

THEOREM 3. In the short run, the imposition of a minimum quality standard on the formal sector raises the output and profits of firms in the formal sector while lowering the output and profits of unregulated firms in the informal sector. Overall, aggregate output expands. Quality rises in the formal sector and remains unchanged elsewhere.

In the long run, firms move from the informal sector to the formal sector, and profits, profit per unit, output, and quality equalize across sectors.

Proof. The imposition of the standard must strictly increase aggregate production of the experience good. For, suppose the contrary. Suppose aggregate quantity falls or remains constant. Then the utility that consumers get from the experience good must weakly decrease. In the informal sector, firms would maintain quality, as equation (7) still holds. So if their goods provide weakly less net utility, the prices of their goods $\left(P^{j}=\theta k_{j}-U(Q)\right)$ must weakly increase. Because the per-unit profit $\left(P^{j}-c\left(k_{j}\right)\right)$ would then weakly increase, equation (6) implies that output at each unregulated firm must weakly increase. As for the regulated firms in the formal sector, their per-unit profit must strictly increase, because the standard raised quality and, by assumption, was not excessive $\left(\bar{k}<k^{*}\right)$. Equation (6) then implies that output at each regulated firm strictly increases, but then we have a contradiction: aggregate output cannot weakly decrease as we hypothesized, as this implies that the sum of the individual firm outputs would strictly increase.

So the imposition of a minimum quality standard in one market must cause aggregate output of the experience good to strictly increase and hence must cause the net utility of every consumer of the good to increase. As the quality of the unregulated firms in the informal sector does not change, their prices, profit per unit, output, and total profits must fall. Because aggregate output expands despite the contraction at every unregulated firm, output at every regulated firm must increase, but, as equation (6) implies, regulated firms would expand output only if their profit per unit also increased. Hence, their total profits would also increase. Because profit per unit increases at each regulated firm, its price per unit must increase by more than enough to offset the increased cost per unit of producing the higher quality mandated by the minimum quality standard.

In the long run, firms will abandon the informal sector and join the formal sector. This will raise the quality of the product in the informal market, while the quality in the formal market remains fixed at the level imposed by the minimum quality standard. Note that equation (6) implies that if profit per unit is higher in one sector, then 
output is higher in that sector, which implies profit is higher. Thus, in long-run equilibrium, profit per unit and output must be equalized across sectors. Because profit per unit $\left(\theta k_{j}-U(Q)-c\left(k_{j}\right)\right.$, for $\left.j=F, I\right)$ is equalized across sectors, this implies that quality must also be equalized across sectors.

This result is quite interesting. It demonstrates that given the lack of firm traceability with regard to quality, the government can indirectly, yet effectively, regulate the entire market for a good through regulations on only the formal sector. Intuitively, the minimum quality standard actually creates a comparative advantage for the formal sector, which leads firms to move out of the informal sector. As firms leave the informal sector, the collective reputation problem is ameliorated, which endogenously raises the quality of goods in this sector. This process continues until the quality of good in the informal market is exactly equal to the quality specified by the standard.

By setting the standard at $k^{*}$, the government can in fact achieve the socially optimal quality economy-wide, in both the formal and informal sectors. Even though the informal sector is outside the regulatory reach, spillover effects from the regulation on the formal sector and market forces drive quality in this sector to the socially optimal quality. ${ }^{15}$

\section{Conclusion}

In his V. V. Giri Memorial Lecture, Ravi Kanbur (2009) discusses the "informality discourse" in the development literature and notes that the literature would benefit from a more precise specification of the regulations imposed in the formal sector as well as from a recognition that such regulations on firms in the formal sector may induce them to "adjust activity to move out of the ambit of the regulation."

We adopt his suggestion about specifying regulations more precisely. This paper assumes that consumers can purchase a product on either the formal or informal market and can assess the quality of that product only from the collective reputation of the sector where it is produced and sold. In this circumstance, firms will free ride on quality efforts of others in that sector, and as a result, quality provision in each sector will be suboptimal. We show that regulations imposed on only formal sector firms can generate a quality gap between formal market and informal market goods of the class considered. In particular, if a per-unit tax is imposed, some producers will eventually migrate to the informal sector. The reduced free riding among formal sector producers will result in higher quality goods and elevated prices as compared to the informal sector.

The paper additionally demonstrates, however, that regulations on formal sector firms need not always lead to a quality gap in which goods produced in the formal sector are of higher quality. If, for instance, regulators implement a minimum quality standard on producers in the formal sector, firms will be attracted to the regulated sector. The possibility that a regulation may benefit firms in the regulated sector has apparently received little attention. ${ }^{16}$ Under this policy, there is less free riding in the informal sector because fewer firms remain in it and less free riding in the formal sector as a result of the quality standard. Therefore, a minimum quality standard imposed on firms in the formal sector will increase quality in both sectors to the level specified by the standard and will, in fact, eliminate any existing quality gap. 


\section{Appendix}

\section{Existence and Uniqueness of a Non-trivial Symmetric Solution of the First-order Conditions}

In this section, we establish that there exists a unique solution to equations (4) and (5) in which firms within a sector follow symmetric strategies and receive a strictly positive price for the product. ${ }^{17}$

THEOREM 4. There exists a non-trivial solution to equations (4) and (5) in which quality and output choices within sectors are symmetric. ${ }^{18}$ The solution is unique.

Proof. Given the symmetry we are considering, we can write the Kuhn-Tucker conditions as

$$
\begin{aligned}
& q_{j} \geq 0, \quad P^{j}\left(Q, k_{j}\right)+q_{j} P_{1}^{j}\left(Q, k_{j}\right)-c\left(k_{j}\right) \leq 0, \quad \text { c.s. }, \\
& Q=\sum_{j=1}^{N} n_{j} q_{j},
\end{aligned}
$$

and

$$
k_{j} \geq 0, \quad q_{j}\left[P_{2}^{j}\left(Q, k_{j}\right)-n_{j} c^{\prime}\left(k_{j}\right)\right] \leq 0, \quad \text { c.s. }
$$

where $R^{j}=k_{j}$.

To begin, consider the solution to equation (18) given a particular $Q$ and $q_{j}$. If the firm is inactive $\left(q_{j}=0\right)$, then any quality choice will solve the equation. Now let $\tilde{k}_{j}=\left(c^{\prime}\right)^{-1}\left(\theta / n_{j}\right)$. If the firm is active, it is clear that for all $0 \leq Q<\bar{Q}\left(\tilde{k}_{j}\right), \tilde{k}_{j}$ is the unique nonzero solution to equation (18). For $Q \geq \bar{Q}\left(\tilde{k}_{j}\right)$, there is no nonzero solution.

Let us now consider the system of equations given by (16) and (17) when $k_{j}=\tilde{k}_{j}$ for all $j$. Note that $P^{j}\left(0, \tilde{k}_{j}\right)-c\left(\tilde{k}_{j}\right)=\theta \tilde{k}_{j}-c\left(\tilde{k}_{j}\right)>0$ for all $j .{ }^{19}$ Next, define $\hat{Q}\left(\tilde{k}_{j}\right)<\bar{Q}\left(\tilde{k}_{j}\right)$ such that $P\left(\hat{Q}\left(\tilde{k}_{j}\right), \tilde{k}_{j}\right)=c\left(\tilde{k}_{j}\right)$. Then the solution to (16) is $q_{j}=0$ for all $Q \geq \hat{Q}\left(\tilde{k}_{j}\right)$. By totally differentiating equation (16) with respect to $Q$, we find that for $Q<\hat{Q}\left(\tilde{k}_{j}\right)$

$$
\frac{d q_{j}}{d Q}=-\frac{P_{1}^{j}\left(Q, \tilde{k}_{j}\right)+q_{j} P_{11}^{j}\left(Q, \tilde{k}_{j}\right)}{P_{1}^{j}\left(Q \tilde{k}_{j}\right)}=-\frac{G^{\prime}(Q)+q_{j} G^{\prime \prime}(Q)}{G^{\prime}(Q)}<0 .
$$

Now let $f(Q)=\sum_{j=F, I} n_{j} q_{j}(Q)$ and $Q^{H}=\max \left\{\hat{Q}\left(\tilde{k}_{F}\right), \hat{Q}\left(\tilde{k}_{I}\right)\right\}$. Then $f(Q)$ is continuous and strictly decreases from $f(0)>0$ to $f\left(Q^{H}\right)=0$ and $f(Q)=0$ for all $Q \geq Q^{H}$. Thus, the curve will cross the $45^{\circ}$ line exactly once at some $0<Q^{*}<Q^{H}$. Let $k_{j}^{*}=\tilde{k}_{j}$ and $q_{j}^{*}=q_{j}\left(Q^{*}\right)$ for all $j$. If $Q^{*}<\hat{Q}\left(\tilde{k}_{j}\right)<\bar{Q}\left(\tilde{k}_{j}\right)$, then $q_{j}^{*}>0$, and if $Q^{*} \geq \hat{Q}\left(\tilde{k}_{j}\right)$, then $q_{j}^{*}=0$. The profile $\left(\left(k_{j}^{*}\right)_{j=F, I},\left(q_{j}^{*}\right)_{j=F, I}, Q^{*}\right)$ satisfies the Kuhn-Tucker necessary conditions. Note that at least one market will be active, since $Q^{*}<Q^{H}$. 


\section{Nonexistence of Asymmetric Nash Equilibria}

In this section, we show that the symmetric outcome is the only possible Nash equilibrium.

Theorem 5. There exist no nontrivial pure strategy Nash equilibria in which firms in active markets produce different qualities and/or outputs.

The proof first proceeds by establishing two lemmas which demonstrate that in any nontrivial equilibrium, (1) active firms never produce the minimum quality and (2) active sectors cannot have inactive firms.

Lemma 1. There can be no nontrivial equilibrium (symmetric or otherwise) in which a firm produces a positive quantity of the minimum quality.

Proof. If it is optimal to produce at minimum quality $\left(k_{i j}=0\right)$, then since $c^{\prime}(0)=0$, condition (5) requires that $P_{2}\left(Q, R^{j}\right) \frac{q_{i j}}{Q^{j}} \leq 0$. But each of the factors to the left of this inequality is strictly positive since, by hypothesis, $q_{i j}>0$ and we are considering nontrivial equilibria. So the inequality can never hold. Therefore, every firm with $q_{i j}>0$ must have $k_{i j}>0$.

Intuitively, because the cost function is flat at the origin but inverse demand is strictly increasing in quality when the price is nonzero, an active firm producing a minimal quality can always increase its profit by marginally increasing its quality choice. At the margin, costs will remain the same but the price will increase.

Lemma 2. There can be no nontrivial equilibrium (symmetric or otherwise) in which an active market can have an inactive firm.

Proof. Suppose that $q_{i j}=0$ and $Q^{j}>0$. In that case, one or more of the rival firms is producing a strictly positive amount. Label as firm $i^{\prime}$ the active firm with the smallest quality. Hence, $k_{i^{\prime} j}-R^{j} \leq 0$. Because firm $i^{\prime}$ produces a strictly positive amount, its first-order condition in (4) must hold with equality. Because the terms $q_{i^{\prime} j} P_{1}^{j}\left(Q, R^{j}\right)$ and $q_{i^{\prime} j} P_{2}^{j}\left(Q, R^{j}\right)\left(k_{i^{\prime} j}-R^{j}\right) / Q$ are respectively strictly and weakly negative, (4) implies $P^{j}\left(Q, R^{j}\right)-c\left(k_{i^{\prime} j}\right)>0$. But because the cost function is strictly increasing, $P(Q$, $\left.R^{j}\right)-c(0)>0$, and this same complementary slackness condition, which must hold for firm $i$ as well, implies that $q_{i j}>0$, contradicting the hypothesis that $q_{i j}=0$.

Now consider an active sector $j$. By the two previous lemmas, the first-order conditions of each firm in this sector must hold with equality. That is, the following equation must hold in equilibrium:

$$
\left[k_{i j}-\left(R^{j}-\frac{Q G^{\prime}(Q)}{\theta R^{j}}\right)\right] c^{\prime}\left(k_{i j}\right)+\left\{\theta R^{j}-G(Q)-c\left(k_{i j}\right)\right\}=0 .
$$

Define the left-hand side as $\Gamma^{j}\left(k_{i j} ; Q, R^{j}\right)$. In equilibrium, every firm $\left(i=1, \ldots, n_{j}\right)$ will have $\Gamma^{j}\left(k_{i j} ; Q, R^{j}\right)=0$. However, this equation cannot have more than one root. We see 
that $\frac{\partial \Gamma^{j}}{\partial k_{i j}}\left(k_{i j} ; Q, R^{j}\right)=\left[k_{i j}-\left(R^{j}-\frac{Q G^{\prime}(Q)}{\theta R^{j}}\right)\right] c^{\prime \prime}\left(k_{i j}\right)$, and (20) requires that at any root, the first factor in $\frac{\partial \Gamma^{j}}{\partial k_{i j}}\left(k_{i j} ; Q, R^{j}\right)$ must be strictly negative. ${ }^{20}$

Hence, there can be no more than one root. So for any given equilibrium with its $\left(Q, R^{j}\right)$, a unique $k_{i j}$ satisfies equation (20). But because equation (20) must hold for every firm, each firm must choose the same quality in this equilibrium. Denote it $k_{j}\left(Q, R^{j}\right)$. Moreover, as every firm will be active and reputed quality will equal $R^{j}=k_{j}\left(Q, R^{j}\right)$, equation (4) implies that $q_{i j}=\frac{\theta R^{j}-G(Q)-c\left(k_{j}\left(Q, R^{j}\right)\right)}{-G^{\prime}(Q)}$. Because the right-hand side of this equation is independent of $i$, every firm will produce the same quantity in this equilibrium. Denote it $q_{j}\left(Q, R^{j}\right)$.

\section{References}

Akerlof, George A., “The Market for 'Lemons': Quality Uncertainty and the Market Mechanism," Quarterly Journal of Economics 84 (1970):488-500.

Banerji, Arup and Sanjay Jain, "Quality Dualism," Journal of Development Economics 84 (2007):234-50.

Castells, Manuel and Alejandro Portes, "World Underneath: The Origins, Dynamics and Effects of the Informal Economy," in Portes, Alejandro, Manuel Castells and Lauren A. Benton (eds), The Informal Economy: Studies in Advanced and Less Developed Economies, Baltimore, MD: JHU Press (1989):11-37.

Dessy, Sylvain and Stéphane Pallage, "Taxes, Inequality and the Size of the Informal Sector," Journal of Development Economics 70 (2003):225-33.

Dixit, Avinash K, Lawlessness and Economics: Alternative Models of Governance, Princeton, NJ: Princeton University Press (2004).

Fortin, Bernard, Nicolas Marceau and Luc Savard, "Taxation, Wage Controls and the Informal Sector," Journal of Public Economics 66 (1997):293-312.

Ihrig, Jane and Karine S. Moe, "Lurking in the Shadows: The Informal Sector and Government Policy," Journal of Development Economics 73 (2004):541-57.

International Labour Organisation, "Employment, Incomes and Equality: A Strategy for Increasing Productive Employment in Kenya," International Labour Organisation, Geneva (1972).

Kanbur, Ravi, "Conceptualising Informality: Regulation and Enforcement," Indian Journal of Labour Economics 52 (January-March 2009):33-42.

Klein, Benjamin and Keith B. Leffler, "The Role of Market Forces in Assuring Contractual Performance," Journal of Political Economy 89 (1981):615-641.

Livingstone, Ian, “A Reassessment of Kenya's Rural and Urban Informal Sector,” World Development 19 (1991):651-70.

Marjit, Sugata, Sudeep Ghosh, and Amit Biswas, "Informality, corruption and trade reform," European Journal of Political Economy 23 (2007):777-89.

Marjit, Sugata and Saibal Kar, The Outsiders: Economic Reform and Informal Labour in a Developing Economy, Oxford: Oxford University Press (2011).

Mazumdar, Dipak, "Segmented Labour Markets in LDCs," American Economic Review 73 (1983): 254-59.

McQuade, Timothy J., Stephen W. Salant, and Jason A. Winfree, "Markets with Untraceable Goods of Unknown Quality: Beyond the Small-Country Case," discussion paper 09-31-rev, Resources for the Future, Washington, DC (2012).

Myint, Hla, "Organizational Dualism and Economic Development," Asian Development Review 3 (1985):24-42. 
Rauch, James E., "Modelling the Informal Sector Formally," Journal of Development Economics 35 (1991):33-47.

Shapiro, Carl, "Premiums for High Quality Products as Returns to Reputations," Quarterly Journal of Economics 98 (1983):659-80.

Tirole, Jean, "A Theory of Collective Reputation (with Applications to the Persistence of Corruption and to Firm Quality)," Review of Economic Studies 63 (1996): 1-22.

Winfree, Jason A. and Jill J. McCluskey, "Collective Reputation and Quality," American Journal of Agricultural Economics 87 (2005):206-13.

\section{Notes}

1. There are obviously also intermediate cases.

2. This is different than the models of Shapiro (1983) and Klein and Leffler (1981) in which consumers cannot ascertain quality prior to purchase, but can at least identify the producer of the experience good by scrutinizing its branding or packaging. They therefore base their expectation of the quality of the experience good on the reputation of the firm which produced it. Given that the consumer can identify the producer of the experience good, one firm's quality choice never affects another firm's reputation for quality.

3. The sellers of high quality automobiles in Akerlof (1970) face a similar "collective reputation" problem but quality is exogenous in his model. Tirole (1996) coined the term "collective reputation." However, his focus was not on the strategic interaction of firms but on the reputations of workers.

4. For an overview of the differences between formal and informal, see Dixit (2004). Some of the early discussions of informal markets come from the International Labour Organisation (1972) and Mazumdar (1983).

5. Quality provision in each sector would still be suboptimal from a social welfare perspective as a result of the freeriding problem caused by the collective reputation.

6. See Fortin et al. (1997), Dessy and Pallage (2003), Ihrig and Moe (2004).

7. We make this assumption only for tractability. Considering measure-theoretic analyses where firms are infinitesimal in size changes none of the qualitative results and serves only to add unimportant technical considerations.

8. If the experience good is a "consumable" such as food, the outside option could represent home production. The heterogeneity would then reflect differences in gardening skill and in the time at home which can be devoted to home production.

9. Formally, let $\mu$ be a $\sigma$-finite measure on $[0, \infty)$. Define $Q(G)=\int_{0}^{G} d \mu$. We assume that $Q(0)=0$ and that $Q(G)$ is twice differentiable, strictly increasing, and strictly concave. Let $G(Q) \equiv Q^{-1}(G)$.

10. See McQuade et al. (2012) for a discussion of when the symmetric solution to (4) and (5) constitutes a Nash equilibrium.

11. In this model, it is assumed that output produced in the formal sector is marketed in the formal sector and output produced in the informal sector is marketed in the informal sector. This rules out firms producing in one sector and then disguising their products as originating in the other sector so as to earn higher prices and profits. It also rules out purchasing a good in the sector with the lower price and reselling it in the sector with the higher price.

12. To see this, suppose that aggregate output increases. Since $\theta \geq c^{\prime}\left(k_{I}\right) \geq 0, \frac{d k_{I}}{d n_{I}}<0$, and $G(Q)$ is strictly increasing and convex, it is clear from equation (15) that output contracts in the informal sector, but then if aggregate output increases, it must be that output increases in the formal sector. Similarly, if aggregate output decreases, one can show from equation (14) that output increases in the formal sector, which implies that output decreases in the informal sector.

13. The effect is even more surprising if the government subsidizes formal sector production $(\tau<0)$. Such a subsidy would actually degrade the quality of goods within the ambit of regulation and would effectively raise the quality of goods outside the ambit of regulation. 
14. One form this regulation could take is to require the sellers in the formal market to give their customers a receipt. If the quality of the good was less than that imposed by the standard, the customer could use the receipt to file a legal claim against the seller. If the cost of these suits to the sellers were sufficiently high, sellers would refuse to deal with producers of goods with quality less than that imposed by the government standard. Thus, requiring that sellers in the formal sector furnish receipts is an indirect way of imposing a minimum qualiy standard on producers in the formal sector.

15. The policy is welfare-improving overall in the long run since it increases long run aggregate output. By the discussion above, in the long run the policy is equivalent to a minimum quality standard which is binding on both formal sector and informal sector firms. It is easy to show that such a policy increases aggregate output. For details see McQuade et al. (2012).

16. The idea of a government intervention in one area benefiting agents in another area despite the absence of any intervention in that area has other applications. For example, if a fixed number of motorists commute from the same origin to the same destination on two congestible roads, then expanding one road so that commute time for any given number of cars is reduced will attract motorists from the other road and will therefore reduce the commute time on that other road, even though the government has made no improvements to that road. One can think of other examples where everyone is helped by regulation even those who are not directly subject to it. In the case of the highway expansion, it is quite plausible that commute time will improve on both roads to exactly the same extent. In the case of a minimum quality standard in the formal market, quality is likely to rise in the regulated market. Whether it rises to the same extent in the informal market as our model predicts depends on factors from which we have abstracted. Although a standard might in reality affect quality in the informal market less than in the formal market, the movement of quality in the same direction in the two markets might make identifying empirically the full effects of the regulation a challenge.

17. See McQuade et al. (2012) for a discussion of when the unique symmetric solution to necessary conditions (4) and (5) constitutes a Nash equilibrium.

18. Trivial equilibria are those in which firms receive a price of zero for the product.

19. Let $\hat{k}=\left(c^{\prime}\right)^{-1}(\theta)$. Then since $c(0)=0$ and the cost function is convex, we know $k-c(k)$ is maximized at $\hat{k}$. Since $\tilde{k}_{j} \leq \hat{k}$ for all $j$, it follows that $\theta \tilde{k}_{j}-c\left(\tilde{k}_{j}\right)>0$ for all $j$.

20. The term in braces in (20) must be strictly positive, since $q_{i j}>0$ (from Lemma 2); condition (16) therefore holds with equality, and $P_{1}<0$ by assumption. 